\title{
Who's the Boss? Concepts of Social Power Across Development
}

\author{
Selin Gülgöz and Susan A. Gelman \\ University of Michigan
}

\begin{abstract}
Power differences are observed in children's early relationships, yet little is known about how children conceptualize social power. Study 1 recruited adults $(n=35)$ to assess the validity of a series of vignettes to measure five dimensions of social power. Using these vignettes, Study 2 (149 three- to nine-year-olds, 42 adults) and Study 3 (86 three- to nine-year-olds, 22 adults) showed that children visiting a science museum at a middle class university town are sensitive to several dimensions of social power from a young age; however, an adult-like breadth of power concepts does not develop until 7-9 years. Children understand social power whether the powerful character is malevolent or benevolent, though malevolent power is easier to detect for children and adults.
\end{abstract}

Children are born into systems of social relationships characterized by power. Power dynamics shape relationships within the family, among peers, and in school contexts. Power also characterizes dynamics between and within social groups, including those based on gender, race, and social status (Sidanius \& Pratto, 1999) - concepts that children develop and use from an early age. The ubiquity of power in social relationships, at both the individual and the group levels, implies that developing an understanding of social power is crucial for children to successfully navigate the social world. From an evolutionary standpoint, an earlyemerging concept of social power is adaptive and needed for social competence in recognizing relational dynamics, gaining understanding of culturally appropriate behaviors, predicting others'

This research was supported by the University of Michigan Rackham Graduate Student Research Fellowship and the Rackham Pillsbury Graduate Research Award to Selin Gülgöz, and by NICHD grant HD-36043 to Susan Gelman. We are grateful to the children, parents, and adults who participated in these studies, and the Ann Arbor Hands on Museum, the University of Michigan Museum of Natural History, and the Ann Arbor District Library for their generosity in allowing us to set up Living Lab stations. We would also like to thank our research assistants, Aaron Chuey, Amanda Balakirsky, Anna Wendorf, Donald Alfred Lyons, Jennifer Ashley Asong, Kristina Ljucovic, Natalie Davidson, Pragya Mathur, and Rebecca Sheinman for their hard work. Portions of this research were included in Gülgöz's doctoral dissertation, and were presented at the Biennial Meeting for the Society for Research in Child Development and the Biennial Meeting for Cognitive Development Society in 2015. Images used in these studies were designed by Defne Civelekoglu. We thank Henry M. Wellman, Ramaswami Mahalingam, Robin Queen, and members of the University of Michigan Language and Cognition Lab for their feedback and guidance.

Correspondence concerning this article should be addressed to Selin Gülgöz, Department of Psychology, University of Washington, Guthrie Hall (GTH), 119A 98195-1525, Seattle, WA 98105. Electronic mail may be sent to sgulgoz@uw.edu. behaviors, and knowing which social alliances will be beneficial. Despite extensive ethological research in nonhuman animals' power structures (for a review, see De Waal, 2007), and human adults' sensitivity to social power (for a review, see Sidanius \& Pratto, 1999), surprisingly little is known about the developmental origins of a concept of social power, its predictors, and its consequences. The goal of the present research is to investigate these issues by examining children's understanding of social power differentials as manifested in social interactions.

\section{Origins of Conceptualizing Social Power}

An individual's social world is vast, complex, and dynamic. The primate brain has evolved to support the mapping of a dynamic social world, including the tracking of grooming networks, kinship relations, coalitions, transitive and third-party relations, and quality of relationships with allies and enemies (for a review, see Silk, 2007). The adaptive advantage of such social mappings is to maximize access to limited resources, and thus aid survival (Hawley, 1999; Silk, 2007). Across species, recognizing social power differentials allows individuals to build alliances with powerful others, increasing cooperation and in turn, dominance, leading to superior reproductive success (Cosmides \& Tooby, 1992; De Waal, 2007).

The few recent studies that examine the development of social power concepts suggest that

Child Development (c) 2016 Society for Research in Child Development, Inc. All rights reserved. 0009-3920/2017/8803-0018

DOI: $10.1111 /$ cdev. 12643 
humans may have an early-developing cognitive capacity to recognize power differentials. Thomsen, Frankenhuis, Ingold-Smith, and Carey (2011) presented 8- to 13-month-old infants an animated scene in which two agentic blocks differing in size were depicted as having conflicting goals (i.e., moving in opposite directions along a path with no room to pass one another). In the expected outcome condition of the study, the smaller block bent over and moved aside to allow the larger block to continue on its path and achieve its goal, whereas in the unexpected outcome condition, the larger block bent over and moved aside to allow the smaller block to continue on its path and achieve its goal. Thomsen et al. (2011) found that 10- to 13-month-olds, but not 8-month-olds, looked longer in the unexpected outcome condition, indicating that their expectation of the outcome was violated. The authors interpreted this finding as indicating infants' early capacity to represent social dominance, meaning greater social power, and to expect it to correlate with an agent's size. Brey and Shutts (2015) found that 5- to 6-year-olds, but not 3- to 4-year-olds, showed adult-like sensitivity to a range of nonverbal cues to social power (e.g., upright posture, raised gaze) when asked to indicate who is in charge. Finally, in a study by Charafeddine et al. (2014), French 3- to 5-year-olds were presented with two puppets engaged in a physical fight over two episodes, with the same puppet winning on both instances. When asked "Who is the boss?/C'est qui le chef?," participants selected the puppet that prevailed.

The findings reviewed above indicate children's early sensitivity to nonverbal cues to social power, consistent with extensive research with adults across cultures (Schubert, Waldzus, \& Seibt, 2008) as well as nonhuman primates (for reviews, see Hall, Coats, \& LeBeau, 2005; Schubert et al., 2008). However, the tasks that have been used may only require implicit processing of perceptual cues or attention to inherent physical features, as opposed to more explicit and reflective reasoning about how two individuals relate to each other. Indeed, neuroscientific evidence with adults suggests that detection of nonverbal facial cues to dominance occurs very rapidly-within $200 \mathrm{~ms}$ (Chiao et al., 2008), indicating automatic processing. Several researchers have argued for dual representational systems in conceptual development, where different levels of understanding are attributed to children in infancy and in later childhood (e.g., Mandler, 1988; Wellman \& Gelman, 1992). Thus, an important question is whether and when young children have access to concepts of social power relationships that entail more explicit and inferential reasoning.

\section{Five Dimensions of Power}

To examine children's concepts of social power, we selected five possible manifestations of power that are prevalent in the social power literature. Even though the dimensions were selected to represent distinct facets of social power, we use these dimensions as a set of provisional conceptual distinctions to explore the breadth of children's understanding of social power rather than an exhaustive model of social power. These dimensions are all construed as parts of a broader concept of social power. Thus, there are inevitable conceptual overlaps between the selected dimensions. Below, we briefly describe the five dimensions of power that are the focus of the present experiments: resource control, goal achievement, permission, giving orders, and setting norms.

\section{Resource Control}

Studies of children's peer relationships show that resource control is a common way in which 3- to 6year-old children exert dominance over their peers (e.g., Hawley, 2002). One's access to or control over resources is central to the way in which social power has been construed from an evolutionary perspective (Guinote \& Vescio, 2010; Hawley, 1999). From this point of view, individuals who seek allegiances with those who can access and control resources have better chances of survival. Young children have strong and consistent beliefs about the right ways of allocating resources. By 18-24 months of age children readily share resources (Brownell, Iesue, Nichols, \& Svetlova, 2013), and 3- to 5-year-olds prefer equal distribution of resources (e.g., LoBue, Nishida, Chiong, DeLoache, \& Haidt, 2011; Olson \& Spelke, 2008). At the same time, 3- to 6-year-old children display selfinterested biases, where they tend to share fairly only if there is no cost to themselves (Smith, Blake, \& Harris, 2013). Starting at 4 years of age, there is rich evidence for children's early awareness of the value of resources demonstrated through children's beliefs about ownership and property rights (e.g., Neary, Friedman, \& Burnstein, 2009; Noles \& Gelman, 2014; Shaw, $\mathrm{Li}, \&$ Olson, 2012). Of greatest relevance to the current discussion, 4- to 5-year-olds show preference for those who have more resources, even in the absence of any indication that they themselves will benefit from these resources ( $\mathrm{Li}$ et al., 2014) - thereby showing a capacity to track resource control. This 
behavior suggests that children may infer social power relationships by observing the way in which resources are handled between interacting individuals. In support of this hypothesis, Pietraszewski and Shaw (2015) have shown that 6- to 8-year-olds use resource holding potential as a basis for deciding on outcomes of conflicts over resources, expecting the owner of the resource to win the conflict.

\section{Goal Achievement}

One way in which social power might be manifested is through an individual's or group's ability to achieve their intended goals at the expense of others (Fiske, 1993; Guinote \& Vescio, 2010; Keltner, Gruenfeld, \& Anderson, 2003; Russell, 1938/2004). Studies of social dominance patterns in children's peer relationships in preschool and elementary school show that children who are rated by adults as more powerful tend to be more socially competent and are more likely to manipulate peers to achieve their own goals (Hawley, 2002, 2003). Previous research shows that children have an early understanding of goal-directed and intentional action, grounded in a developing theory of mind (ToM; for a review, see Wellman, 2014). Young children even accurately represent conflicting goals, as long as their own goals are not compromised: when 3-year-olds are asked about two other individuals' conflicting goals, they accurately identify the happy and sad targets based on whose desires were fulfilled in the end (Rakoczy, Warneken, \& Tomasello, 2007; but also see Wright Cassidy et al., 2005). However, although young children understand the emotional consequences of conflicting or unachieved goals, it is unclear whether young children who understand that two individuals' conflicting goals will lead to negative feelings in the one whose goals are not fulfilled will also understand that this asymmetry in the ability to achieve goals reflects power differentials.

\section{Permission}

Another important facet of social power is the ability to control others' outcomes (Fiske, 1993; Keltner et al., 2003). Granting and denying permission are two important means by which such control takes place. Thus, understanding social power relationships manifested in this way may necessitate deontic-reasoning capacities in children; that is, the understanding of social rules governing obligations, permissions, and prohibitions (Dack \& Astington, 2011). Evolutionary theorists argue that deontic reasoning is an innate adaptation that allows one to detect those who violate social contracts (Cosmides \& Tooby, 2008) and to detect and navigate social power hierarchies (Cummins, 1996a). Therefore, children should benefit from an early-emerging understanding of permission in social relationships.

Young children experience power manifested through permission early on, as they are often told what to do by parents and teachers and require their permission for a number of daily activities. Children as young as 3 years of age understand social obligations and permissions (Cummins, 1996b; Dack \& Astington, 2011; Wellman \& Miller, 2008), and make inferences about a person based on whether they give or deny permission (Neary et al., 2009). Four- and 5-year-old children use shared deontic properties (e.g., being allowed to feed pigs) to make attributions of social category membership between two individuals (Kalish \& Lawson, 2008). Given children's early understanding of deontic relations, which is a crucial understanding for representing social power relationships, it was expected that children from a young age will represent social power in terms of permission.

\section{Giving Orders}

A leader's ability to give others orders to divide labor is another prevalent form of social power. Although nonhuman primates may display some form of division of labor (e.g., recruiting partners to collaborate for a mutual goal, Melis, Hare, \& Tomasello, 2006), the capacity to give verbal orders to elicit leadership and followers is uniquely human (for a review, see King, Johnson, \& Van Vugt, 2009). This sort of leadership behavior is prevalent in children's early peer relationships. When elementary school children are asked to evaluate their peers, leadership, popularity, and social dominance are found to go hand in hand (for a review, see Rubin, Bukowski, \& Parker, 2006). Preschoolers and 7- to 11-year-olds follow orders of both peers and adults when they are presented as authority figures (Kim, 1998; Laupa, 1994). Although young children experience leadership and are sensitive to its implications, it is unclear if they construe giving orders as a manifestation of power.

\section{Setting Norms}

Because of their implications for shared intentionality, social norms are considered to be unique 
to humans and a relatively recent adaptation (Rakoczy \& Schmidt, 2013). Norms stress the evolutionary pressures to be similar to others in your group, leading to the enhancement of withingroup similarities and intergroup differences (Tomasello, 2009). Social norms can be explicitly stated (e.g., a powerful child announcing the rules to a game) or implicitly manifested (e.g., others imitating a powerful child's appearance or behaviors). As powerful individuals are most likely to be imitated, admired, and sought as allies by others (Hawley, 1999), it is important to include this facet of power in an examination of children's concepts.

Developmental evidence supports the importance of imitation in individual and group relations. Starting from 14 months of age, children attend to models' former success and expertise when deciding whom to imitate (Koenig \& Harris, 2005; Williamson, Meltzoff, \& Markman, 2008; Zmyj, Buttelmann, Carpenter, \& Daum, 2010). Three- to 5-year-old preschoolers also prefer to learn a new action from a prestigious adult model to which others had previously attended than from an adult model that others had previously ignored (Chudek, Heller, Birch, \& Henrich, 2012; McGuigan, 2013; for similar work with adults, see Atkisson, O'Brien, \& Mesoudi, 2012), and those who have been labeled as smart rather than not smart (Lane, Wellman, \& Gelman, 2013). Fiveyear-olds use imitative behavior patterns to infer affiliation and relative status in third-party relationships (Over \& Carpenter, 2015). Furthermore, 5 -year-olds primed with videos showing an individual excluded from a group showed greater imitation of an in-group model compared to children in a control condition (Over \& Carpenter, 2009). Together, these findings suggest that children may be sensitive to imitation in third-party relations, and able to use these relationships to infer dominance and group norms.

\section{Social Power and Valence}

Historically, social psychological perspectives on the purpose of power have been divided into dominance perspectives and functionalist perspectives (Overbeck, 2010). In this dichotomy, dominance perspectives define power structures as expressed through violence and based on oppression, discrimination, and the exploitation of people for a powerful person's or elite group's own benefits (Dépret \& Fiske, 1993; Russell, 2004; Sidanius \& Pratto, 1999). Examples are frequent in human history (e.g., genocide, racism). In contrast, functionalist perspectives suggest that, due to the interdependence of individuals in a society, power inheres in one or a few individuals who then can carry out the interests of the larger group (Russell, 2004). Power relationships are viewed as necessary and beneficial, and the person in power works for others' best interests. Thus, although the dominance view defines power as corrupt and vicious, the functionalist view defines it as an organizational factor that benefits the group.

As previously described, a widely held perspective on conceptualizing social power is that, recognizing power hierarchies provides adaptive advantage for individuals in maximizing chances of survival (e.g., Hawley, 1999; Silk, 2007). Evolutionary forces enable individuals in both human and nonhuman primate groups to readily recognize power structures so that they can identify potential alliances that will benefit them (e.g., Cosmides \& Tooby, 1992). From this perspective, it should also be important for individuals to easily recognize both dominance and functionalist power structures. Examples of both dominance (e.g., bullying as a means of maintaining dominance) and functionalist power (e.g., parents and teachers exerting power for the advancement of children) are commonplace in children's everyday experiences. To understand the breadth of children's conceptualization of social power, it is important to examine their ability to identify those who are in power both when they present as malevolent and benevolent.

\section{The Present Studies}

The present experiments examine children's and adults' concepts of social power relationships between individuals, and advance our understanding of children's concepts of social power in three primary ways. First, we examined several distinct respects in which power may be manifested. Second, we included participants across a wide age range (early preschool through elementary school and adults) in order to map out the developmental trajectory of social power concepts. Third, participants' concepts of power were assessed in situations where the powerful character could be conceived as either malevolent or benevolent in order to determine understanding of both positive and negative manifestations of power.

In Study 1, we first pretested our measures with adult participants to ensure the validity of the five 
dimensions reviewed above: resource control, goal achievement, permission, giving orders, and setting norms. Using the vignettes pretested in Study 1, Study 2 examined children's (3- to 9-year-olds) and adults' concepts of social power by asking them to identify the character who is "in charge," in each of the 10 vignettes. Finally, in Study 3, we tested children's and adults' conceptualization of power when the powerful character is benevolent (e.g., distributes resources equally), as a comparison to Studies 1 and 2, in which the powerful characters could be interpreted as relatively malevolent. Together, the three studies provide a comprehensive examination of children's developing understanding of social power.

We had four key predictions. First, we expected the capacity to reason about social power to emerge early in development, given its hypothesized evolutionary basis and significance for social functioning. Second, we expected that as children's social cognitive abilities to represent mental states and social relationships developed, their proficiency at using different cues to social power would increase. Third, we predicted different developmental trajectories for the different dimensions. Specifically, the first two dimensions (resource control and goal achievement) were expected to develop earlier compared to the last three (permission, giving orders, and setting norms). Although resource control and goal achievement situations can pertain exclusively to individuals, and conceptualized as such, situations involving permission, giving orders, and setting norms require dyadic interactions. Therefore, power dynamics born from these concepts, due to the very definition of social power, will be relational. Thus, we predict that children's early understanding of resource control and goal achievement might allow them to more easily represent social power relationships that arise in these situations. Additionally, resource control and goal achievement appear to be earlier adaptations that humans share with nonhuman primates, as contrasted with the last three dimensions, which require deontic reasoning and advanced ToM capacities, that may be later adaptations unique to human evolution (Tomasello, 2009). Although evolutionary precedence certainly does not necessitate ontological precedence, the increased requirement of advanced social cognitive skills might drive the same order in development. Finally, because recognizing social power relationships is believed to be an adaptive function, we expected that children would represent both malevolent and benevolent forms of power early on.

\section{Study 1}

Method

\section{Participants}

Participants were 35 adults $(M=35.18$ years; 13 females) recruited online through Amazon MTurk. All adults resided in the United States, as determined by their IP addresses. All testing was done online through the use of a survey designed on Qualtrics. On the first page of the survey, participants received a consent form that they had to agree to in order to continue onto the study. At the end of the study, participants were given the option to have their data deleted. However, no one requested to do so. Participants received $\$ 0.50$ for their participation. Adults were not asked to provide additional demographic data.

\section{Materials and Procedure}

The survey consisted of 10 test vignettes (Appendix S1). For each vignette, participants were instructed to select any of the following descriptors that they thought best described a predetermined character in the story: controls resources, achieves own goals, denies permission, sets norms, and bosses around. They were free to select any number of descriptors per vignette. These descriptors corresponded to the dimensions that were being tested. Vignettes were presented in randomized order for each participant. The order in which the powerful character was presented in each vignette was counterbalanced across trials.

\section{Results and Discussion}

Results confirmed that the vignettes assessed the five hypothesized dimensions. For each vignette, the majority of participants selected the descriptor consistent with the initially predicted dimension (see means for all vignettes in Table 1). Because participants were given a binary decision in which they could select more than one dimension for each vignette, each vignette was compared to chance (.5) via a one-sample $t$ test. These tests showed that participants selected the predicted dimension as the best descriptor significantly above-chance level for every vignette. For 9 of the 10 vignettes, none of the other dimensions were selected above chance. The one exception was the "Ball" vignette (designed to assess permission), for which participants also selected a second descriptor (resource control) significantly above chance. 
Table 1

Adults' Judgments of Vignette-Dimension Validity (Study 1)

\begin{tabular}{lccccc}
\hline & Resource control (RC) & Goal achievement $(\mathrm{GA})$ & Permission $(\mathrm{P})$ & Giving orders $(\mathrm{GO})$ & Setting norms (SN) \\
\hline Toy truck (RC1) & $.77^{*}[.13, .42]$ & $.66[-.01, .32]$ & $.4[-.27, .07]$ & $.31[-.35,-.02]$ & $.06[-.52,-.36]$ \\
Candy (RC2) & $.86^{*}[.24, .48]$ & $.66[-.01, .32]$ & $.26[-.40,-.09]$ & $.17[-.46,-.20]$ & $.06[-.52,-.36]$ \\
Bridge (GA1) & $.17[-.46,-.20]$ & $.83^{*}[.20, .46]$ & $.23[-.42,-.13]$ & $.17[-.46,-.20]$ & $.17[-.46,-.20]$ \\
Dessert (GA2) & $.26[-.40,-.90]$ & $.80^{*}[.16, .44]$ & $.2[-.44,-.16]$ & $.37[-.30, .04]$ & $.29[-.37,-.06]$ \\
Ball (P1) & $.69^{*}[.02, .35]$ & $.17[-.46,-.20]$ & $.91^{*}[.32, .51]$ & $.46[-.22, .13]$ & $.11[-.50,-.27]$ \\
Castle (P2) & $.57[-.10, .24]$ & $.2[-.44,-.16]$ & $.94^{*}[.36, .52]$ & $.6[-.07, .27]$ & $.09[-.51,-.32]$ \\
Blocks (GO1) & $.34[-.32, .01]$ & $.29[-.37,-.06]$ & 0 & $.91^{*}[.32, .51]$ & $.23[-.42,-.13]$ \\
Clean-up (GO2) & $.23[-.42,-.13]$ & $.34[-.32,-.01]$ & $.03[-.53,-.41]$ & $.86^{*}[.24, .48]$ & $.23[-.42,-.13]$ \\
Red t-shirt (SN1) & $.11[-.50,-.27]$ & $.31[-.35,-.02]$ & $.06[-.52,-.36]$ & $.4[-.27, .07]$ & $.94 *[.36, .52]$ \\
Badge (SN2) & $.09[-.51,-.32]$ & $.31[-.35,-.02]$ & 0 & $.57[-.10, .24]$ & $.97^{*}[.41, .53]$ \\
\hline
\end{tabular}

Note. Numbers show participants' mean proportion of endorsements [95\% confidence interval] for each power dimension in each vignette. In Study 1, adult participants were asked to select what they thought was the best descriptors (they were able to select multiple responses) for the target character in each vignette. Mean responses were compared to chance (.5). Vignette-dimension pairings of interest are shown in bold. Scores that were above chance are indicated $\left({ }^{*} p<.05\right)$.

That participants selected the predicted dimensions for all vignettes, and selected a second dimension only for one of the vignettes, validated the vignettes by indicating that they depicted the five dimensions of power that were intended to assess.

\section{Study 2}

Study 2 examined children's and adults' conceptions of who is in charge in situations depicting power dynamics across the five dimensions of interest. Using the vignettes tested in Study 1, we asked participants to select the more powerful ("in charge") character in each of the 10 depicted situations, as well as for two control items (height and an irrelevant dimension). Participants also provided open-ended explanations for their selections, to assess the reasoning behind their choices.

\section{Method}

\section{Participants}

Participants were fifty-five 3 - to 4-year-olds $(M=4.10$, age range $=3.05-4.98,28$ females $)$, fiftythree 5- to 6-year-olds $(M=5.87$, age range $=5.01$ $6.95,32$ females), forty-four 7- to 9-year-olds $(M=8.30$, age range $=7.02-9.95,30$ females $)$, and 42 adults $(M=28.59$, age range $=18.14-39.61,17$ females). Child participants were recruited through a local children's museum in a predominantly middle-class university town in Midwestern U.S.A. Adults were recruited online through MTurk, recruitment procedures being identical to Study 1 .
Participation was voluntary for both children and adults. As compensation, children received a small toy and adults received $\$ 0.50$. Written parental consent and child verbal assent were achieved for all child participants prior to testing. Adult participants provided consent before participating. Data were excluded from an additional eight children who did not complete the study: four 3- to 4-yearolds, two 5- to 6-year-olds, and two 7- to 9-yearolds. Data were excluded from an additional 15 adults whose age exceeded the predetermined range (18-40 years). (MTurk does not allow prescreening participants during recruitment.) Data for Study 1 and following studies were collected between July 2014 and June 2015.

\section{Materials and Procedure}

Children were tested individually by an experimenter using the questionnaire created on Qualtrics. Adults participated individually through MTurk, by accessing a Qualtrics link leading to the adult version of the questionnaire. The only differences between the two questionnaires were the consent and debrief procedures. Both questionnaires included the same 10 vignettes that were tested in Study 1. In each vignette, participants saw two hand-drawn figures of the same shape and size, wearing similar but distinct clothing patterns. Characters within each vignette were also given similar novel names (e.g., Twip and Kwip), to minimize potential associations. Character gender matched that of the participant, to control for possible preexisting assumptions about power and gender. Character appearances and names were pretested with a 
separate sample of 31 adults through MTurk to make sure that adults did not have prior assumptions about the gender of the characters in the images. With the exception of one permission vignette and one resource control vignette, participants judged the characters as having the same gender. As an added measure, the assignment of characters to power roles was counterbalanced across participants, with 112 participants receiving one assignment (A) and 81 receiving the other assignment (B). In order to control for possible order effects, the position of the powerful character was counterbalanced across the two vignettes within each dimension, such that the powerful character was on the left for one vignette, and on the right for the other vignette.

Each experimental session began with instructions pointing out that the characters were the same gender as the participant, and that they were all the same age. After each vignette, participants were asked, "Who is in charge? [Name of first character] or [name of second character]?" The name of each character was written underneath it. With child participants, the experimenter also pointed at the relevant character each time its name was mentioned in the script, and pointing responses were permitted. After each response, participants were also asked to explain their selection: "How do you know?"

The test vignettes were presented in randomized order. After receiving all 10 test vignettes, participants were given two additional control vignettes, in fixed order. In the irrelevant control, the two characters differed on an irrelevant dimension (i.e., one drew a yellow house with an orange roof, the other drew an orange house with a yellow roof), and we expected participants to select at chance. In the height control, two characters differed in height, and we expected that participants would select the taller character. This trial was always shown at the very end. These control trials were exploratory and are not included in the remainder of this article (see Appendix S2 for a sample trial of the task).

\section{Coding and Analysis}

Participants received 1 point on each trial they identified the character predicted to be more powerful on the test trials, as well as 1 point for identifying the taller figure on the height control trial; all other responses received 0 points.

In addition to scoring participants' performance on individual vignettes, several composite scores were calculated. First, composite scores for each dimension of power were created by summing participants' scores for the two vignettes in each dimension, yielding five separate dimension scores for each participant (resource control, goal achievement, setting norms, permission, giving orders). The maximum possible score for these individual dimension composites was 2 (if a participant selected the predicted character on both vignettes within a dimension), with chance level at 1 . Second, a total composite score was calculated, which was equal to the sum of all five composite dimension scores. Thus, the maximum possible score for the total composite was 10 (if a participant selected the predicted character on every vignette), chance level was 5, and the minimum possible score was 0 (if a participant selected the opposite character on every test trial).

For the open-ended questions that followed each of the vignettes, each response was coded as either "relevant dimension" or "other." Responses were coded as "relevant dimension" and received 1 point if they identified the dimension that the power relationship was intended to depict, or identified the main element of the story that made the character more powerful. All other responses were coded as "other" and received 0 points. Two experimenters independently coded a randomly selected $20 \%$ of the data (39 participants) to achieve coding reliability. Because the content of the relevant dimension codes varied across each of the five dimensions, the coding reliability was calculated separately for each dimension. Results for the coding reliability (agreement, kappa) were as follows: resource control $(92 \%, .83)$, goal achievement $(92 \%, .84)$, permission $(92 \%, .85)$, giving orders $(82 \%, .63)$, and setting norms $(90 \%, .77)$. The two experimenters reconciled discrepancies, and one of the experimenters completed the remaining coding. The relevant dimension codes were tallied to create the two-level composites identical to those created for the forcedchoice responses: individual dimension scores (resource control, goal achievement, permission, giving orders, setting norms) and a total composite score.

\section{Results}

\section{Choices}

First, to examine participants' performance on each of the dimensions of power, a repeated measures analysis of variance was carried out with dimension (resource control, goal achievement, permission, giving orders, setting norms) as the 
within-subjects variable, and age group (3- to 4year-olds, 5- to 6-year-olds, 7- to 9-year-olds, adults) and assignment (assignment $\mathrm{A}$, assignment B) as between-subjects variables. Results are shown in Figure 1. There was a significant main effect of age group, $F(3,185)=25.99, p<.001, \eta_{p}^{2}=.30$. Post hoc pairwise comparisons showed that each age group performed significantly better than all of the preceding age groups $(p s<.01)$. There was also a significant main effect of assignment, $F(1$, $185)=4.10, p=.04, \eta_{p}^{2}=.02$, with those receiving assignment $\mathrm{B}(M=1.62)$ showing a small but consistent advantage compared to those receiving assignment A $(M=1.51)$. The Age Group $\times$ Order interaction was not significant, $F(3,185)=0.76$, $p=.52, \eta_{\mathrm{p}}^{2}=.01$.

Importantly, there was a significant main effect of dimension, $F(4,740)=4.50, p=.001, \eta_{p}^{2}=.02$. Post hoc Bonferroni comparisons showed that participants performed better on permission vignettes $(M=1.68)$ than on goal achievement $(M=1.50$, $p=.01)$ and giving orders $(M=1.46, p=.005)$. Performance on the other dimensions did not vary significantly from each other. This effect was subsumed under the significant Dimension $\times$ Age Group interaction, $F(12,740)=1.95, p=.03$, $\eta_{\mathrm{p}}^{2}=.03$. Post hoc comparisons showed that 7- to 9-year-old children and adults performed similarly on all dimensions except for permission, where adults $(M=1.98)$ performed better than 7- to 9year-olds $(M=1.65, p=.016)$. Adults performed better than all other age groups (3- to 4-year-olds and 5- to 6-year-olds) on all dimensions. Seven- to 9-year-olds performed better than 5- to 6-year-olds on resource control $(p=.04)$ and giving orders $(p<.001)$, and they performed better than 3- to 4year-olds on all dimensions but permission $(p=.17)$. Finally, 5- to 6-year-olds performed better than 3- to 4-year-olds on goal achievement $(p=.04)$ and setting norms $(p=.01)$. Any effects not reported here were nonsignificant. These results indicate the piecemeal fashion through which children's sensitivity to social power emerges across development. As opposed to being a unitary concept, sensitivity to different aspects of social power seems to come online at different points of development.

Next, to examine participants' overall tendency to infer power differences in the given vignettes, each age group's mean total composite score was compared to chance (chance level $=5$ ). Results showed that the overall scores for all age groups were significantly above chance $(p s<.001)$. In addition to understanding participants' relative sensitivity to social power across the dimensions, we conducted a series of one-sample $t$ tests comparing each age group's performance on each dimension to chance (chance level $=1$ ). Results indicated that

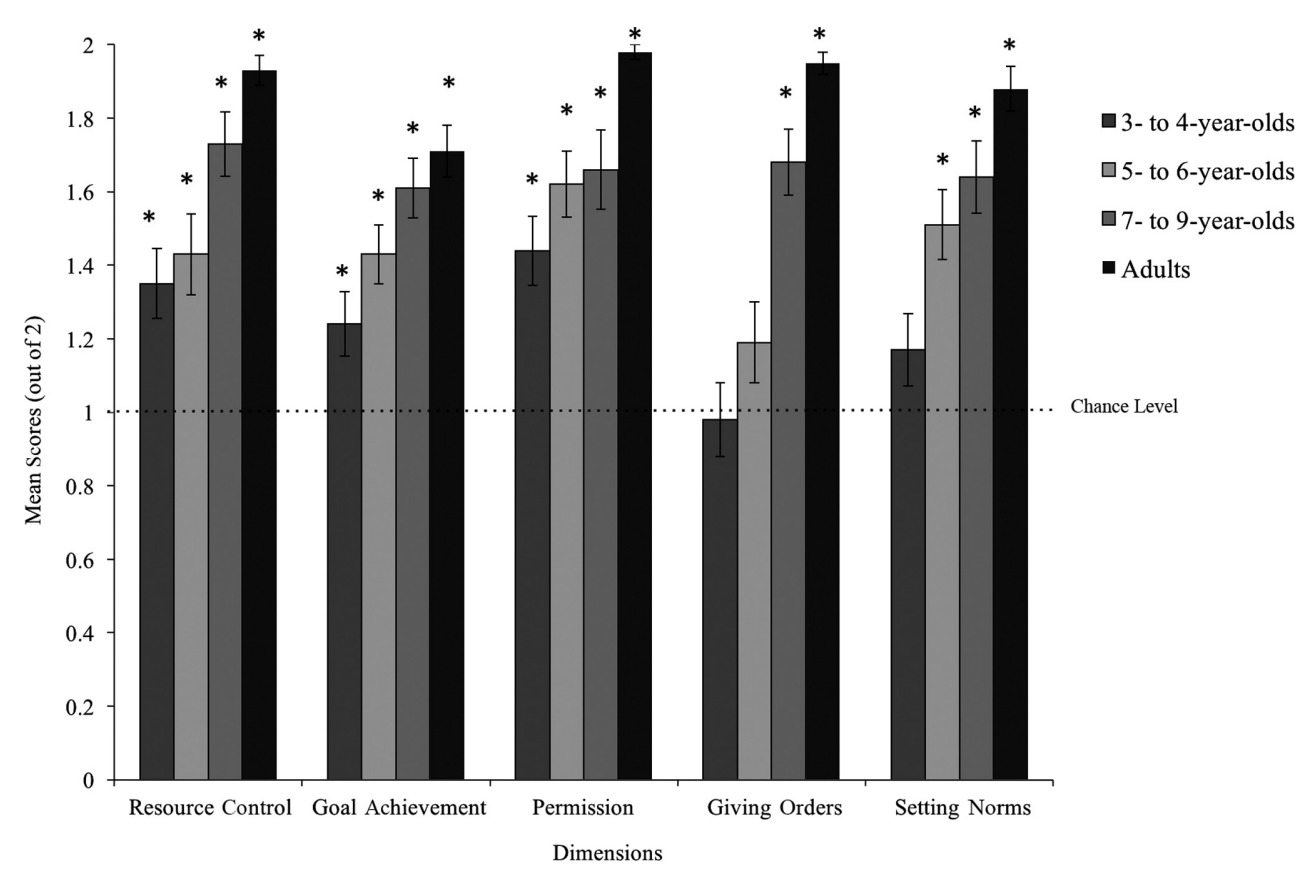

Figure 1. Study 2: Mean scores on each dimension for each age group in choice questions ("Who is in charge?"). Score for each dimension is a composite sum of the scores of the two relevant vignettes. Scores that are significantly above chance are indicated $(* p<.05)$. 
all age groups scored above chance on resource control ( $p s \leq .001)$, goal achievement ( $p s \leq .008)$, and permission $(p s<.001)$. Three- to 4 -year-olds scored at chance on giving orders and setting norms, and 5- to 6-year-olds scored at chance on giving orders. Seven- to 9-year-olds and adults scored above chance on all dimensions. Thus, children as young as 3-4 years of age show a clear understanding of power differentials in the resource control, goal achievement, and permission vignettes that we presented. However sensitivity to power in other dimensions appears to emerge later in development (setting norms does not emerge until age 5, and giving orders does not emerge until age 7).

\section{Explanations}

A similar analysis plan was followed up for participants' explanations in response to the follow-up questions ("How do you know?"). Open-ended responses were scored as 1 (dimension relevant) or 0 (other). A repeated measures analysis of variance was conducted with dimension as the within-subjects variable, and age group and assignment as the between-subjects variables. Results were similar to those found for the choices. There was a significant main effect for age group, $F(3,185)=39.09$, $p<.001, \eta_{p}^{2}=.39$, indicating that all age groups identified the relevant dimension significantly more than the preceding age groups ( $p s<.003$ ), except that adults and 7- to 9-year-olds performed similarly $(p=.06)$. There was a main effect for dimension, $F(4,740)=16.65, p<.001, \eta_{p}^{2}=.08$. Post hoc comparisons showed that participants provided the most dimension-relevant responses for resource control, giving orders, and setting norms. Both of these main effects were subsumed under the significant Age Group $\times$ Dimension interaction, $F(12$, $740)=3.86, p<.001, \eta_{\mathrm{p}}^{2}=.06$. Post hoc comparisons showed that 3- to 4-year-olds provided the most dimension-relevant responses for resource control, which was significantly higher than all other dimensions ( $p s<.02)$, and the least dimension-relevant responses for permission, which was significantly lower than all other dimensions (ps < .04). Further examination of 3- to 4-year-olds' responses showed that $24 \%$ of their dimension nonrelevant responses on permission items pertained to resource control, whereas $13 \%$ pertained to permission and $44 \%$ were irrelevant to the task. Five- to 6year-olds provided the most dimension-relevant responses for resource control and setting norms, both of which were higher than all other dimensions ( $p$ s <.04). Similar to 3- to 4-year-olds, 5- to 6- year-olds provided the least dimension-relevant responses for the permission dimension, which was significantly below all other dimensions $(p s<.01)$. Seven- to 9-year-olds performed highest on resource control, giving orders, and setting norms ( $p s<.02)$, and equally low on goal achievement and permission. Adults provided the most dimension-relevant responses for permission, giving orders, and setting norms ( $p \mathrm{~s}<.01)$, and the lowest dimension-relevant responses for goal achievement ( $p$ s $<.005)$. Finally, there was a main effect for assignment, $F(1$, $185)=4.15, p=.04, \eta_{p}^{2}=.02$, indicating a slight advantage for those in assignment $\mathrm{B}(M=1.35)$ compared to those in assignment A $(M=1.19)$, though assignment did not interact with age group or dimension.

\section{Discussion}

In Study 2, 3- to 9-year-olds children and adults were presented with vignettes that were confirmed in Study 1 to map onto five hypothesized dimensions of social power: resource control, goal achievement, permission, giving orders, and setting norms. Results showed that even the youngest participants noticed social power differentials for the resource control, goal achievement, and permission dimensions. The findings also showed a clear developmental trajectory, such that children did not link social power to setting norms until ages 5-6 (despite that in these vignettes the norms were explicitly stated, which presumably should make them more salient), nor to giving orders until ages 7-9. These results are consistent with Mascaro and Csibra's (2012) and Thomsen et al.'s (2011) findings showing that even preverbal infants may be sensitive to power relationships in resource control and goal achievement situations, and support our prediction based on comparative studies with nonhuman primates (Tomasello, 2009) that social power would be understood with regard to resource control and goal achievement sooner than with regard to other dimensions requiring understanding deontic relations. The results are also consistent with Pietraszewski and Shaw's (2015) findings of 6- to 8year-olds children's sensitivity to resource ownership in conflict situations. Surprisingly, however, even the youngest children in this sample were also sensitive to permission (also a deontic relation) in their selections of the individual in charge. Because 3- and 4-year-olds provided the lowest number of dimension-relevant responses for the permission dimension, we further examined the types of explanations children in this age group provided. 
Although the youngest children consistently interpreted permission denial as reflecting power differences, the dimension nonrelevant explanations they provided suggest that they may have interpreted those vignettes as indicating imbalances in resource control rather than permission. A large portion of children in this age group did not provide any interpretable explanations. Youngest children's conflation of resource control and permission makes sense when the vignettes are considered: In both permission vignettes, the character in charge is denying the other character the use of a resource (i.e., playing with a ball, going inside a castle). Thus, although a majority of adults' explanations of these vignettes were about permission, for the younger children, resource control may have been a stronger cue to social power.

Together, these results show that preschool children are aware of social power differentials between individuals. Importantly, their understanding of social power goes beyond recognizing implicit, nonverbal cues to include more complex manifestations, including the control of resources, the achievement of desired goals at the expense of others, and the capacity to deny permission. Over development, children also begin to understand more nuanced forms of social power that require representation of social obligations and norms.

\section{Study 3: Children's Concepts of Benevolent Power}

Results of Study 2 indicate that children have acquired a dominance perspective of power by ages 3-4 years, meaning that they easily represent malevolent manifestations of power (e.g., not giving permission, taking more candy). These findings raise the question of whether children are sensitive to more functionalist aspects of power, and whether they are able to represent benevolent power as well as malevolent power.

Prior research indicates that children are highly sensitive to benevolent (prosocial, "nice") and malevolent (antisocial, "mean") behavior from a young age. Even infants show marked preferences for prosocial individuals (Hamlin, Wynn, \& Bloom, 2007, 2010), and preschool-age children make friendship judgments based on nice versus mean trait information. For example, 4- to 6-year-olds (but not 3-year-olds) show strong friendship preferences for those who are smart, nice, and honest (as opposed to not smart, mean, and dishonest; Lane et al., 2013), 5- and 6-year-olds show friendship preferences for those who speak with a foreign accent but are nice, as opposed to those who speak with a native accent but are mean (despite showing strong preferences for native accented speakers when all else is equal; Kinzler \& DeJesus, 2013), and preschoolers use traits like "nice" and "mean" in making inferences about people (for a review, see Heyman, 2009).

Although children's sensitivity to benevolence and malevolence is increasingly well documented, how children's judgments of benevolence and malevolence fit into their concepts of social power is less clear. One possible prediction is that children may at first conflate malevolence with power, as illustrated by an anecdote shared by the father of a 3-year-old participant in Study 2: His child had recently declared that she knew which of her two teachers was the one in charge (although in fact they were equally in charge). When asked why, she said that the meaner teacher was more in charge. Participants in Study 2 occasionally made similar comments in response to the vignettes. Thus, an important question is whether and when children can conceptualize power independent of meanness.

Study 3 was designed to examine children's understanding of social power when the powerful character behaved in a benevolent manner. By using a protocol similar to that used in Study 2 but depicting benevolent powerful characters, Study 3 also provides an important control to test that what is measured in Study 2 is indeed children's inferences about social power relations and not their perceptions of meanness.

\section{Method}

\section{Participants}

Participants were thirty-two 3- to 4-year-olds $(M=4.33$, age range $=3.11-4.97$ years, 20 females $)$, twenty-six 5- to 6-year-olds $(M=6.01$, age range $=5.03-6.90$ years, 17 females), twenty-eight 7- to 9-year-olds $(M=8.10$, age range $=7.15$ 9.88 years, 16 females), and 22 adults $(M=26.71$, age range $==18.19-36.78$ years, 11 females). Recruitment method was identical to Study 2. Data from three additional children (2 aged 3-4, 1 aged 7-9) were dropped: one child participant was not fluent in English, and two children said they did not know what "in charge" meant. Data from nine adults were dropped because their ages were not within the predetermined age range of 18-40 years, and because MTurk does not allow recruiting participants of selected age groups. 


\section{Materials and Procedure}

The present study presented a modified version of the protocol from Study 2 to measure children's and adults' perceptions of benevolent power. A subset of the dimensions used in Study 2 for which all age groups showed sensitivity (resource control, goal achievement, and permission) were selected in order to ensure that our measure tapped into even youngest children's concepts of power. Vignettes of these dimensions were modified to depict the more powerful characters as having benevolent intentions. For example, in Study 2, one permission vignette (Ball) was, "Grup was playing with a ball. Trup asked Grup, 'Can I play too?' Grup told Trup, 'No, you cannot.'" In contrast, the wording of the comparable vignette for this study was, "Grup was playing with a ball. Trup asked Grup, 'Can I play too?' Grup told Trup, 'Yes, you can.'” Appendix S3 lists the scripts of these new vignettes. As in Study 2, participants were randomly assigned to one of two orders of presentation.

To ensure that the original and modified vignettes for the three dimensions differed from each other in terms of malevolence-benevolence, we conducted a pretest with 23 additional adults $(M=28.75$, range $=21-41$ years $)$ recruited through MTurk, none of whom participated in the main study. In this pretest, participants were given written text (no pictures) of both the malevolent and benevolent items in randomized order. Participants were asked to rate the protagonist in each story on a 5-point Likert scale ranging from 1 (mean) to 5 (nice). Paired $t$ tests of the composite scores for each dimension (i.e., ranging from 2 [mean] to 10 [nice]) showed that the modified benevolent versions of all three dimensions (resource control, $M=9.13$; goal achievement, $M=9.26$; permission, $M=9.43$ ) were judged as significantly nicer than their original malevolent versions (resource control, $M=4.39$; goal achievement, $M=6.04$; permission, $M=2.74$; ps $<.001)$.

The procedure of the main task was identical to that of Study 2, with the exception of the openended question following each vignette, which was changed from "How do you know?" (Study 2) to "Why is X in charge?" (Study 3). Participants did not receive the control trials.

\section{Coding}

The scoring of the choice questions and the coding of the open-ended questions were identical to Study 2.
Results

\section{Choices}

In order to examine participants' sensitivity to benevolent power in the three dimensions of social power, a repeated measures analysis of variance was carried out with dimension (three levels: resource control, goal achievement, permission) as the within-subjects variable, and age group (four levels: 3- to 4 year-olds, 5- to 6 year-olds, 7- to 9year-olds, adults) as the between-subjects variable. Preliminary analyses showed no significant order effects, so order was not included as a variable in subsequent analyses. There was a significant main effect of age group, $F(3,101)=7.89, p<.001$, $\eta_{\mathrm{p}}^{2}=.19$. Post hoc pairwise comparisons showed that 3- to 4-year-olds $(M=1.18)$ performed significantly worse than 7 - to 9-year-olds $(M=1.54$, $p=.002)$ and adults $(M=1.71, p<.001)$, and that 5 - to 6 -year-olds $(M=1.35)$ performed significantly worse than adults $(p=.004)$. There was also a significant main effect of dimension, $F(2,202)=23.31$, $p<.001, \eta_{p}^{2}=.19$. Post hoc comparisons indicated that performance on all three dimensions were significantly different from each other $(p s<.001)$, with the lowest performance on goal achievement $(M=1.16)$ and the highest performance on permission $(M=1.70)$. No other significant effects were found in this analysis.

Participants' dimension scores were also compared to chance (3) with a series of one-sample $t$ tests conducted with each age group's overall score. Results showed that the overall score for each age group was significantly above chance $(p s<.04)$. Each age group's mean scores on each of the dimensions were also compared to chance (1). Although 3- to 4-year-olds were above chance only on permission, $t(31)=3.46, p=.002$, 5- to 6-yearolds and 7- to 9-year-olds performed above chance for resource control and permission $(p s<.03)$. Adults performed above chance on all three dimensions $(p s<.03)$. Figure 2 shows age groups' mean performances on each dimension.

\section{Explanations}

Using an analysis plan parallel to the one used for the choice responses, we conducted a repeated measures analysis of variance with dimension (three levels: resource control, goal achievement, permission) as the within-subjects variable, and age group (four levels: 3 - to 4 year-olds, 5- to 6 yearolds, 7- to 9-year-olds, adults) as the between-subjects variable. There was a significant main effect of 


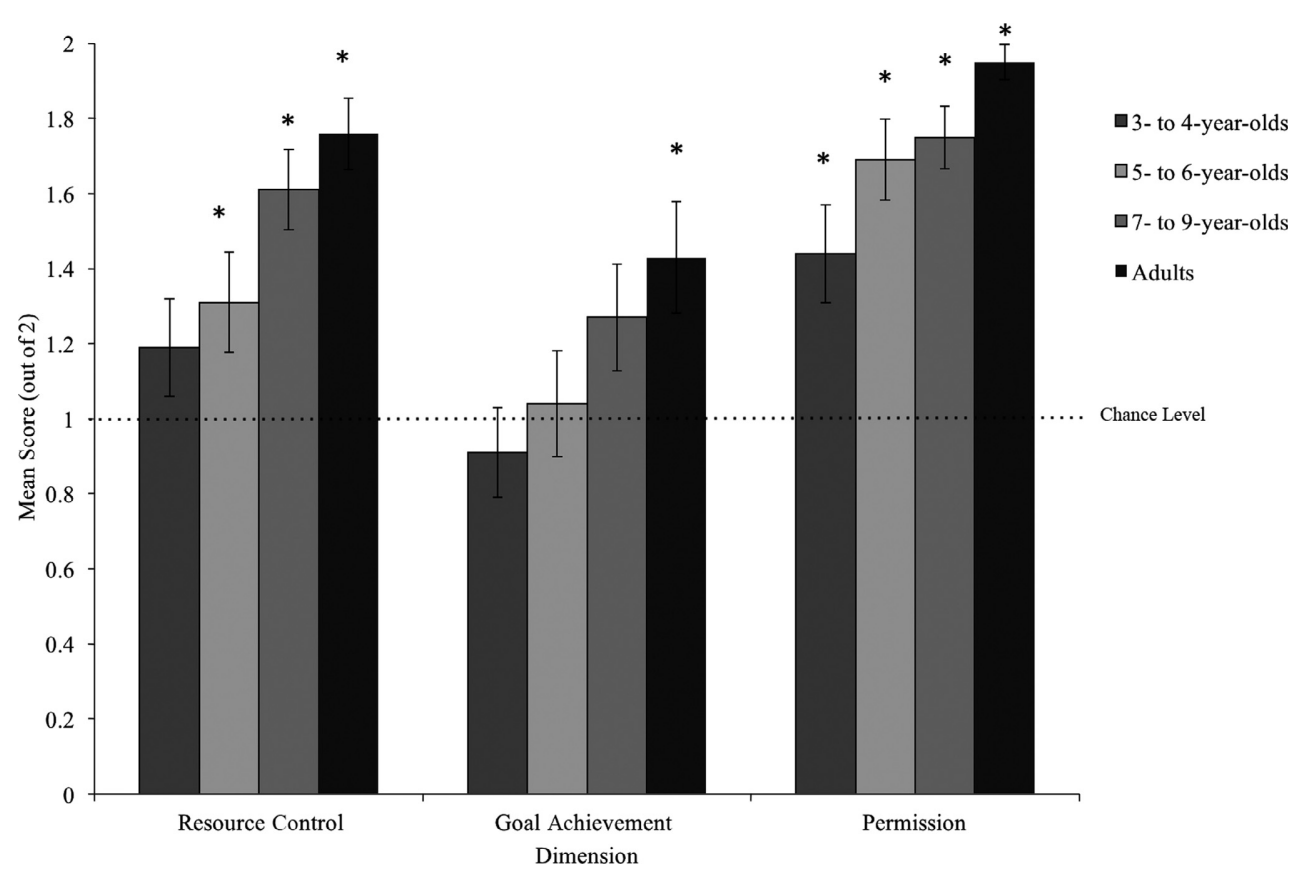

Figure 2. Study 3: Mean scores on each dimension for each age group in choice questions ("Who is in charge?"). Score for each dimension is a composite sum of the scores of the two relevant vignettes. Scores that are significantly above chance are indicated $(* p<.05)$.

age group, $F(3,101)=17.15, p<.001, \eta_{\mathrm{p}}^{2}=.34$. Post hoc comparisons showed that 3 - to 4-year-olds $(M=0.33)$ performed significantly lower than all other age groups, with adults $(M=1.51)$ providing the most dimension-relevant responses, and 5- to 6year-olds $(M=1.12)$ and 7 - to 9-year-olds $(M=1.15)$ performing similarly to each other. There were no other significant effects in this analysis.

\section{Comparing Malevolent and Benevolent Power}

To directly compare responses to the benevolent power items in Study 3 with the corresponding dimensions in Study 2, a repeated measures analysis of variance was carried out with dimension (resource control, goal achievement, permission) as the within-subjects variable, and age group and study (Study 2, "malevolent"; Study 3, "benevolent") as the between-subjects variables (see Figure 3). Here, we report only those significant effects involving study, as all other factors are redundant with the analyses already reported.

Results showed a significant main effect for study, $F(1,292)=9.02, p=.003, \eta_{p}^{2}=.03$. Overall, participants performed significantly better when judging malevolent than benevolent vignettes ( $M s=1.60$ and 1.44, respectively). Moreover, there was a significant two-way interaction between Dimension $\times$ Study, $F(2, \quad 584)=8.46, \quad p<.001$, $\eta_{\mathrm{p}}^{2}=.03$. Post hoc comparisons showed that participants in the malevolent power study (Study 2) scored higher than participants in the benevolent power study (Study 3) on resource control and goal achievement, but not permission. There were no interactions of Age Group $\times$ Study or Age Group $\times$ Study $\times$ Dimension.

\section{Discussion}

Overall, these results indicate that children as young as 3 and 4 years of age represent social power relationships even when the powerful character is benevolent. Thus, Study 3 supports the notion that children's concepts of social power are not limited to situations of malevolent dominance. However, identifying social power relationships in situations where the powerful character was malevolent was easier than when the powerful character was benevolent, both for children and adults.

While even 3- and 4-year-olds' total scores were above chance, the three dimensions yielded different developmental trajectories. For 3- and 4-yearolds, although their overall scores did not differ significantly from 5- to 6-year-olds', the only dimension where sensitivity was observed was permission. Indeed, children showed an early and consistent understanding that giving permission indicates power as strongly as denying permission. By 5-6 years of age, children also showed 


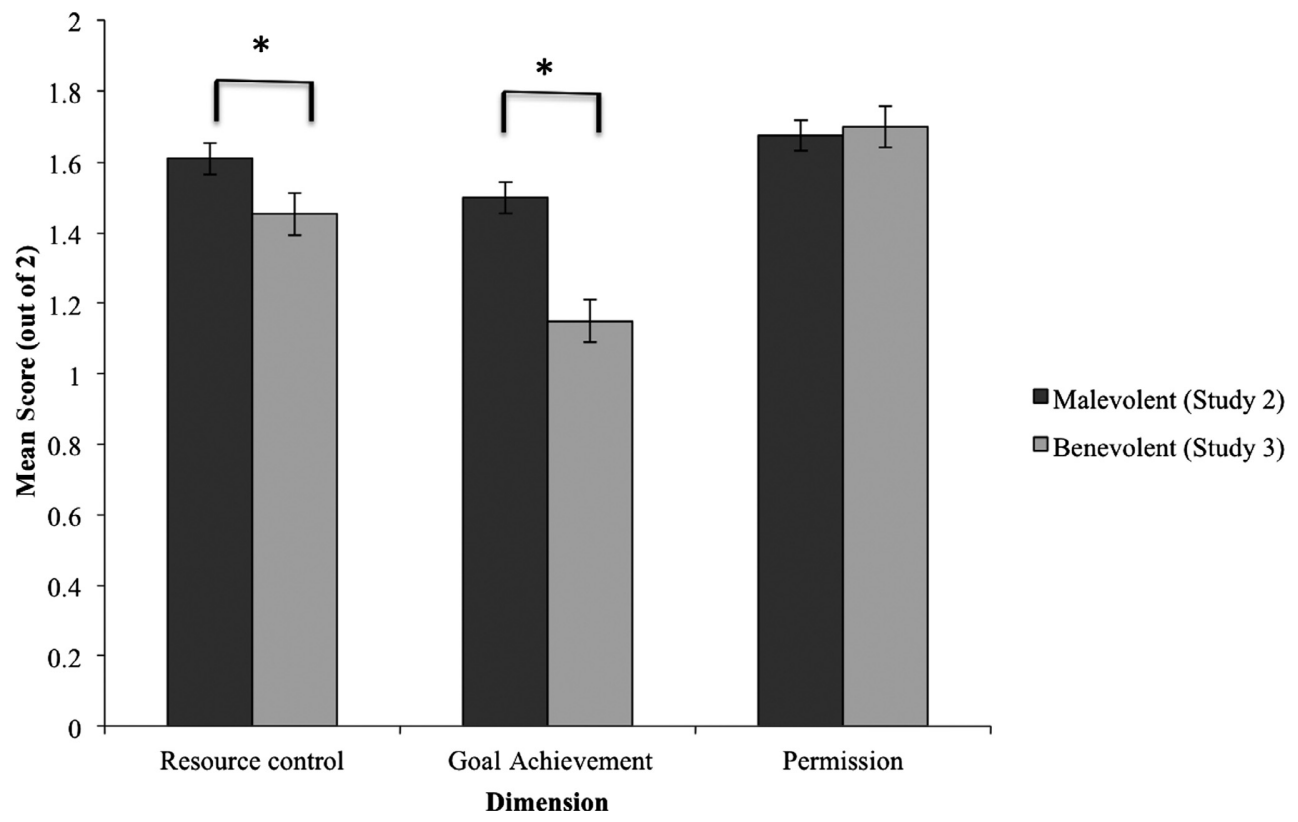

Figure 3. Comparison of mean scores on choice questions of Study 2 and Study 3. Significant pairwise differences are indicated $\left({ }^{*} p<.05\right)$.

sensitivity to resource control in selecting the powerful character. However, only adults used goal achievement in determining the powerful character.

It is interesting that children and adults were not as sensitive to the resource control and goal achievement dimensions when the character was benevolent as when the character was malevolent. These findings suggest that understanding malevolent power is easier than understanding benevolent power, even for adults. Children's and adults' ease of recognizing malevolent power relative to benevolent power might be explained through possible evolutionary adaptations to easily recognize antisocial others. Researchers have suggested that negative behaviors (e.g., meanness) are conceptually privileged, as their early recognition in others may be crucial for survival (e.g., Cacioppo \& Berntson, 1999). Such a negativity bias-where negative information is attended to, utilized, and remembered to a greater degree than positive information-is found in young children as well as adults (e.g., Hamlin et al., 2010; Vaish, Grossmann, \& Woodward, 2008), and may help explain the differences found across the two studies.

In addition to the adaptive advantage of recognizing malevolent power early in development, understanding benevolent power may require more sophisticated cognitive skills than understanding malevolent power. For example, ethological studies of preschoolers and older children have shown that dominant children's successful use of a combination of coercive and aggressive strategies (as opposed to just aggressive strategies) for establishing and maintaining social power among peers are predicted by higher performance on ToM tasks (Pellegrini et al., 2011).

One further point is that benevolent and malevolent power differences are not simply inverses of one another, but entail different processes and mechanisms by which power is manifest. To illustrate, the goal achievement vignettes in Study 3, though superficially the inverse of those in Study 2, changed in their implications. In the benevolent goal achievement vignettes, the more powerful character is the one who yields to the other character. Thus, the yielding character demonstrates power by showing initiative and decision-making capacity, but does not end up achieving his or her intended goal. This is in contrast to the malevolent goal achievement vignettes, in which the more powerful character demonstrates power more by brute force. Thus, children's lack of sensitivity to the goal achievement dimension may reflect this change in meaning, and the increased subtlety in the cues to power.

\section{General Discussion}

In three studies, we examined children's and adults' conceptualization of social power as an aspect of interindividual relationships. Given the complexity 
and multidimensionality of social power, we studied the development of sensitivity to five possible manifestations of social power: resource control, goal achievement, permission, giving orders, and setting norms. Across three studies, 3- to 9-yearolds children and adults were asked to infer which of two individuals had more power. Results showed that even 3- to 4-year-olds were sensitive to social power differences manifested through resource control, goal achievement, and permission. Understanding of setting norms emerged at 56 years of age, whereas understanding of giving orders emerged at 7-9 years. Thus, by ages 7-9, children showed adult-like understanding of how social power characterizes interpersonal relationships in the five dimensions tested.

Moreover, children's sensitivity to social power was not limited to their understanding of power as mean or malevolent. As Study 3 demonstrated, children as young as 3-4 years of age extend their concepts of social power relationships to permission situations where the powerful individual gives permission to the one who asks for it. Five- to 6-yearolds also accurately attributed social power in resource control vignettes where the powerful character shares a toy with the other individual, or divides resources up evenly even though he or she has access to all resources. Around 7-9 years of age, children also represent deferring as a sign of power, where the powerful individual in the goal achievement situations was identified as the one explicitly yielding the right of way or decision making.

These results add to the existing body of research with infants (Mascaro \& Csibra, 2012, 2014; Thomsen et al., 2011) and preschoolers (Brey \& Shutts, 2015) showing early sensitivity to nonverbal cues to social power. In addition, although the exact dimensions used differ, the results are consistent with Charafeddine et al.'s (2014) findings that 3- to 5-year-old children are able to accurately identify the "boss" across scenarios depicting a physical fight, a verbal argument, a wealth discrepancy, and an age asymmetry.

These studies add to previous findings in several important ways. First, they provide a broader developmental scope through the inclusion of 3- to 9-year-old children and adults, and demonstrate the piecemeal fashion in which a multidimensional concept of social power develops. Although an understanding of social power as manifested through resource control, goal achievement, and permission was apparent early in development, sensitivity to giving orders and setting norms emerged later in development.
In addition, the early emergence of sensitivity to resource control and goal achievement is consistent with evolutionary theories of social power (for reviews, see Cummins, 1996a; Hawley, 1999). Because control over resources and achievement of goals can be fundamental to species survival, it is likely that these capacities are part of an adaptive cognitive system that is tuned to recognize social power hierarchies (Cosmides \& Tooby, 1992). In contrast, understanding social power in situations of permission, giving orders, and setting norms requires the ability to represent social and moral obligations and shared intentionality. For these reasons, and the lack of examples of these behaviors in nonhuman primate groups, it is believed that these capacities are relatively recent adaptations in human evolution (Rakoczy \& Schmidt, 2013; Tomasello, 2009). However, the evolutionary account may not be sufficient to explain the developmental patterns in children's power concepts. The types of social interactions children experience are bound to change with age. As children gain further experience with different social situations, the adaptive benefit of recognizing social power might allow children to map their concept of social power onto the different social situations they come to experience.

One surprising result was that permission emerged as an early-developing manifestation of power for young children, despite the predictions provided above. Children correctly identified who was in charge both when the character denied (Study 2) and gave (Study 3) permission to another individual. One possible explanation is that the use of resources (i.e., the castle, the ball) in the permission vignettes may have drawn participants' attention to the resource control dimension. Because participants are sensitive to resource control as a manifestation of power early on, if they interpreted the situation as permission over resources (as opposed to permission to participate in an activity including resources), they may have made power judgments more easily. Alternatively, young children might simply experience permission situations frequently and early on, which might lead to heightened sensitivity specifically to permission, contrary to what we had predicted.

The second major contribution of the work described here is demonstrating the breadth of children's understanding, by examining their concepts of benevolent as well as malevolent social power. Prior work examining children's concepts of social power relationships has focused on powerful characters that could be interpreted as malevolent or 
neutral (neither wholly malevolent nor benevolent; e.g., Charafeddine et al., 2014). Thus, in prior studies it was unclear whether children were responding to power differentials or the dominant character's meanness. For example, in one vignette, two puppets engaged in a physical fight, where one puppet consistently won. Three- to 5-year-olds accurately identified the winner as the "boss" (Charafeddine et al., 2014). In the present studies, even in depictions of power that could be interpreted as malevolent, every effort was made to avoid drawing children's attention to aggression rather than power. That children understood power differentials even when the powerful characters were benevolent provided an additional demonstration that the task assessed concepts of power.

Importantly, although children showed sensitivity to both malevolent and benevolent forms of social power, comparing results of the malevolent and benevolent power studies revealed that understanding malevolent power is easier than understanding benevolent power. The lack of age group differences in these findings suggest that identifying a powerful character is easier even for adults when the character is depicted as malevolent than benevolent. Thus, both adults and children may conflate power and malevolence to a degree, where identifying power across some manifestations (i.e., resource control, goal achievement) is perhaps more straightforward when the powerful character is mean and selfish. Understanding benevolent power might require attention to more subtle cues. Compared to malevolent power, benevolent power implies concealed intentions. From the perceiver's point of view, whereas in malevolent power behaviors the causal relation between intention and action is clear and straightforward, for benevolent power behaviors, the relation between intention and action may not be as clear. In order to represent benevolent power accurately, both the particular cues to social power and the agent's choice to use their power for a benevolent purpose need to be understood. Moreover, in benevolent power, the agent's power comes from a capacity to act (e.g., the capacity to take all resources) as opposed to the action itself (e.g., taking all of the resources); however, this capacity is not enacted (e.g., the agent shares resources evenly). Thus, descriptions of a powerful individual's benevolent acts may not include as many cues to social power as do seemingly malevolent acts, and therefore benevolent displays of power may be more difficult for children to understand.

There are alternative factors that might explain our findings that understanding of malevolent power occurs earlier than understanding of benevolent power. As mentioned previously, because negative information is more salient and privileged in human thought (e.g., Cacioppo \& Berntson, 1999; Hamlin et al., 2010; Vaish et al., 2008), participants may have conceptualized malevolent power more readily than benevolent power. Additionally, because negative information is attended to more, malevolent vignettes may have led to deeper processing on the task, than benevolent vignettes.

\section{Limitations and Future Directions}

We had predicted that evolutionary preparedness for recognizing social power paired with children's early experiences with different types of social relationships would lead to specific developmental patterns across the five dimensions. Although our findings support this theoretical prediction, the design of our study does not allow for a separate examination of the differential contributions of these factors to children's conceptions of social power.

In the studies described here, we examined children's and adults' concepts of social power across five distinct dimensions. Adults' evaluations of how relevant each vignette was to the different dimensions and the varying developmental patterns we found suggest that these dimensions capture a wide range of ways in which power might be conceptualized. However, these studies do not permit strong conclusions regarding the distinctiveness of the dimensions. Nonetheless, the main purpose of these studies was to capture concepts of social power across a range of possible instantiations. Future efforts are needed to map out a set of distinct and exclusive power dimensions.

Despite these limitations, the present studies demonstrate that children have an early-emerging and complex understanding of social power across various possible manifestations. Our findings open up several intriguing questions for future research examining children's conceptualization of social power both at the individual and group level. As a first step in studying power concepts, we studied a predominantly middle-class U.S. sample. Data for the studies were collected in a children's museum in a college town, where many child participants likely came from highly educated and egalitarian families. Factors such as family size and structure may influence the developmental trajectory of power concepts, as they may relate to the prevalence of different types of social interactions in children's early experiences. For example, a child 
growing up in a household with clearly defined gender- or age-based hierarchies might be sensitive to power differentials early on, compared to a child growing up in a more egalitarian household. In future research, it will be important to consider the role of demographic characteristics such as racial, ethnic, or religious background, family structure, and family size. Additionally, the larger cultural context that children grow up in will likely influence their ability to recognize social power differentials. For example, children growing up in cultural contexts where everyday interactions are more readily marked by social hierarchies (e.g., cultures where speakers' relative ages are marked in language), might become sensitive to cues to social power earlier in development. These variables could be important in both understanding contextual influences on the development of a concept of social power, and predicting the generalizability of findings from this study.

\section{Conclusion}

Social power relationships are complex, dynamic, and ubiquitous. Power structures are found universally in human as well as nonhuman primate societies, and they constrain relationships both at the individual and group level. Developing an early understanding of social power is adaptive, in that it allows one to build allegiances with the right individuals or groups in access to resources and opportunities for reproduction. Recognizing social power structures early on also allows children to learn necessary skills to successfully navigate their social plane. The studies presented here add to the newly emerging developmental body of literature on how children develop an understanding of social power, by showing that young children are sensitive to several ways in which social power relationships are manifested.

In a recent discussion, Spelke (2015) suggested that studies of children's early-developing concepts of social power might unveil a new area of study for cognitive development, a conceptual domain that she called naïve sociology (see also Hirschfeld, 1999). Naïve sociology is not only distinct from naïve physics and naïve psychology, but also a domain that develops on top of the latter two, such that an understanding of social power may require the understanding of physical laws of power (e.g., larger is more powerful than smaller), psychological laws of power (e.g., intentions govern power), and social laws of power (e.g., roles within larger social interactions govern power;
Spelke, 2015). The studies presented here are one of the first steps contributing to our understanding of children's conceptualization of the social interactional aspects of power. However, further research is necessary to better understand whether conceptualizing power indeed necessitates the study of a new domain of knowledge, or whether it can be understood as part of other cognitive capacities. By better understanding the ways in which children acquire knowledge about power relationships (e.g., innate preparedness, learning, foundational theories), we might be able to answer these big questions.

\section{References}

Atkisson, C., O’Brien, M. J., \& Mesoudi, A. (2012). Adult learners in a novel environment use prestige-biased social learning. Evolutionary psychology, 10, 519-537. doi:10.1177/147470491201000309

Brey, E., \& Shutts, K. (2015). Children use nonverbal cues to make inferences about social power. Child Development, 86, 276-286. doi:10.1111/cdev.12334

Brownell, C. A., Iesue, S. S., Nichols, S. R., \& Svetlova, M. (2013). Mine or yours? Development of sharing in toddlers in relation to ownership understanding. Child Development, 84, 906-920. doi:10.1111/cdev.12009

Cacioppo, J. T., \& Berntson, G. G. (1999). The affect system architecture and operating characteristics. Current Directions in Psychological Science, 8, 133-137. doi:10. $1111 / 1467-8721.00031$

Charafeddine, R., Mercier, H., Clément, F., Kaufmann, L., Berchtold, A., Reboul, A., \& Van der Henst, J. B. (2014). How preschoolers use cues of dominance to make sense of their social environment. Journal of Cognition and Development, 16, 587-607. doi:10.1080/ 15248372.2014.926269

Chiao, J. Y., Adams, R. B., Peter, U. T., Lowenthal, W. T., Richeson, J. A., \& Ambady, N. (2008). Knowing who's boss: fMRI and ERP investigations of social dominance perception. Group Processes and Intergroup Relations, 11, 201-214. doi:10.1177/1368430207088038

Chudek, M., Heller, S., Birch, S., \& Henrich, J. (2012). Prestige-biased cultural learning: Bystander's differential attention to potential models influences children's learning. Evolution and Human Behavior, 33, 46-56. doi:10.1016/j.evolhumbehav.2011.05.005

Cosmides, L., \& Tooby, J. (1992). Cognitive adaptations for social exchange. In J. H. Barkow, L. Cosmides, \& J. Tooby (Eds.), The adapted mind: Evolutionary psychology and the generation of culture (pp. 163-228). New York, NY: Oxford University Press.

Cosmides, L., \& Tooby, J. (2008). Can a general deontic logic capture the facts of human moral reasoning? How the mind interprets social exchange rules and detects cheaters. In W. Sinnott-Armstrong (Ed.), Moral psychology (pp. 53-119). Cambridge, MA: MIT Press. 
Cummins, D. D. (1996a). Evidence of deontic reasoning in 3-and 4-year-old children. Memory E Cognition, 24, 823829. doi:10.3758/BF03201105

Cummins, D. D. (1996b). Dominance hierarchies and the evolution of human reasoning. Minds and Machines, 6, 463-480. doi:10.1007/BF00389654

Dack, L. A., \& Astington, J. W. (2011). Deontic and epistemic reasoning in children. Journal of Experimental Child Psychology, 110, 94-114. doi:10.1016/j.jecp.2011.04.003

De Waal, F. (2007). Chimpanzee politics: Power and sex among apes. Baltimore, MD: Johns Hopkins University Press.

Dépret, E., \& Fiske, S. T. (1993). Social cognition and power: Some cognitive consequences of social structure as a source of control deprivation. In G. Weary, F. Gleicher, \& K. L. Marsh (Eds.), Control motivation and social cognition (pp. 176-202). New York, NY: Springer. doi:10.1007/978-1-4613-8309-3_7

Fiske, S. T. (1993). Controlling other people: The impact of power on stereotyping. American Psychologist, 48, 621-628. doi:10.1037/0003-066X.48.6.621

Guinote, A., \& Vescio, T. K. (Eds.) (2010). The social psychology of power. New York, NY: Guilford.

Hall, J. A., Coats, E. J., \& LeBeau, L. S. (2005). Nonverbal behavior and the vertical dimension of social relations: A meta-analysis. Psychological Bulletin, 131, 898-924. doi:10.1037/0033-2909.131.6.898

Hamlin, J. K., Wynn, K., \& Bloom, P. (2007). Social evaluation by preverbal infants. Nature, 450, 557-559. doi:10.1038/nature06288

Hamlin, J. K., Wynn, K., \& Bloom, P. (2010). Threemonth-olds show a negativity bias in their social evaluations. Developmental Science, 13, 923-929. doi:10.1111/ j.1467-7687.2010.00951.x

Hawley, P. (1999). The ontogenesis of social dominance: A strategy-based evolutionary perspective. Developmental Review, 19, 97-132. doi:10.1006/drev.1998.0470

Hawley, P. H. (2002). Social dominance and prosocial and coercive strategies of resource control in preschoolers. International Journal of Behavioral Development, 26, 167-176. doi:10.1080/01650250042000726

Hawley, P. H. (2003). Strategies of control, aggression, and morality in preschoolers: An evolutionary perspective. Journal of Experimental Child Psychology, 85, 213235. doi:10.1016/S0022-0965(03)00073-0

Heyman, G. D. (2009). Children's reasoning about traits. Advances in Child Development and Behavior, 37, 105-143. doi:10.1016/S0065-2407(09)03703-3

Hirschfeld, L. A. (1999). Naive sociology. In R. A. Wilson \& F. Keil (Eds.) The MIT encyclopedia of the cognitive sciences (pp. 579-580). Cambridge, MA: MIT Press.

Kalish, C. W., \& Lawson, C. A. (2008). Development of social category representations: Early appreciation of roles and deontic relations. Child Development, 79, 577593. doi:10.1111/j.1467-8624.2008.01144.x

Keltner, D., Gruenfeld, D. H., \& Anderson, C. (2003). Power, approach, and inhibition. Psychological Review, 110, 265-284. doi:10.1037/0033-295X.110.2.265
Kim, J. M. (1998). Korean children's concepts of adult and peer authority and moral reasoning. Developmental Psychology, 34, 947. doi:10.1037/0012-1649.34.5.947

King, A. J., Johnson, D. D., \& Van Vugt, M. (2009). The origins and evolution of leadership. Current Biology, 19, R911-R916. doi:10.1016/j.cub.2009.07.027

Kinzler, K. D., \& DeJesus, J. M. (2013). Children's sociolinguistic evaluations of nice foreigners and mean Americans. Developmental Psychology, 49, 655-664. doi: $10.1037 / \mathrm{a} 0028740$

Koenig, M. A., \& Harris, P. L. (2005). Preschoolers mistrust ignorant and inaccurate speakers. Child Development, 76, 1261-1277. doi:10.1111/j.1467-8624.2005. 00849.x

Lane, J. D., Wellman, H. M., \& Gelman, S. A. (2013). Informants' traits weigh heavily in young children's trust in testimony and in their epistemic inferences. Child Development, 84, 1253-1268. doi:10.1111/ cdev.12029

Laupa, M. (1994). "Who's in charge?" Preschool children's concepts of authority. Early Childhood Research Quarterly, 9, 1-17. doi:10.1016/0885-2006(94)90026-4

Li, V., Spitzer, B., \& Olson, K. R. (2014). Preschoolers reduce inequality while favoring individuals with more. Child development, 85, 1123-1133. doi:10.1111/ cdev.12198

LoBue, V., Nishida, T., Chiong, C., DeLoache, J. S., \& Haidt, J. (2011). When getting something good is bad: Even three-year-olds react to inequality. Social Development, 20, 154-170. doi:10.1111/j.1467-9507.2009.00560.x

Mandler, J. M. (1988). How to build a baby: On the development of an accessible representational system. Cognitive Development, 3, 113-136. doi:10.1016/0885-2014(88) 90015-9

Mascaro, O., \& Csibra, G. (2012). Representation of stable social dominance relations by human infants. Proceedings of the National Academy of Sciences of the United States of America, 109, 6862-6867. doi:10.1073/ pnas.1113194109

Mascaro, O., \& Csibra, G. (2014). Human infants' learning of social structures: The case of dominance hierarchy. Psychological Science, 25, 250-255. doi:10.1177/ 0956797613500509

McGuigan, N. (2013). The influence of model status on the tendency of young children to over-imitate. Journal of Experimental Child Psychology, 116, 962-969. doi:10.1016/j.jecp.2013.05.004

Melis, A. P., Hare, B., \& Tomasello, M. (2006). Chimpanzees recruit the best collaborators. Science, 311, 1297-1300. doi:10.1126/science.1123007

Neary, K. R., Friedman, O., \& Burnstein, C. L. (2009). Preschoolers infer ownership from "control of permission." Developmental Psychology, 45, 873. doi:10.1037/ a0014088

Noles, N. S., \& Gelman, S. A. (2014). You can't always want what you get: Children's intuitions about ownership and desire. Cognitive Development, 31, 59-68. doi:10.1016/j.cogdev.2014.02.002 
Olson, K. R., \& Spelke, E. S. (2008). Foundations of cooperation in young children. Cognition, 108, 222-231. doi:10.1016/j.cognition.2007.12.003

Over, H., \& Carpenter, M. (2009). Priming third-party ostracism increases affiliative imitation in children. Developmental Science, 12, F1-F8. doi:10.1111/j.14677687.2008.00820.x

Over, H., \& Carpenter, M. (2015). Children infer affiliative and status relations from watching others imitate. Developmental Science, 18, 917-925. doi:10.1111/desc.12275

Overbeck, J. R. (2010). Concepts and historical perspectives on power. In A. Guinote \& T. K. Vescio (Eds.), The social psychology of power (pp. 19-45). New York, NY: Guildford.

Pellegrini, A. D., Van Ryzin, M. J., Roseth, C., Bohn-Gettler, C., Dupuis, D., Hickey, M., \& Peshkam, A. (2011). Behavioral and social cognitive processes in preschool children's social dominance. Aggressive Behavior, 37, 248-257. doi:10.1002/ab.20385

Pietraszewski, D., \& Shaw, A. (2015). Not by strength alone: Children's conflict expectations follow the logic of the asymmetric war of attrition. Human Nature, 26, 44-72. doi:10.1007/s12110-015-9220-0

Rakoczy, H., \& Schmidt, M. F. (2013). The early ontogeny of social norms. Child Development Perspectives, 7, 17-21. doi:10.1111/cdep.12010

Rakoczy, H., Warneken, F., \& Tomasello, M. (2007). "This way!," "No! That way!"-3-year- olds know that two people can have mutually incompatible desires. Cognitive Development, 22, 47-68. doi:10.1016/j.cogdev.2006.08.002

Rubin, K. H., Bukowski, W. M., \& Parker, J. G. (2006). Peer interactions, relationships, and groups. In $\mathrm{N}$. Eisenberg (Ed.), Handbook of child psychology (Vol. III, pp. 619-700). Hoboken, NJ: Wiley.

Russell, B. (2004). Power: A new social analysis. New York, NY: Routledge. (Original work published 1938)

Schubert, T. W., Waldzus, S., \& Seibt, B. (2008). The embodiment of power and communalism in space and bodily contact. In G. R. Semin \& E. R. Smith (Eds.), Embodied grounding: Social, cognitive, affective, and neuroscientific approaches (pp. 160-183). Cambridge, UK: Cambridge University Press.

Shaw, A., Li, V., \& Olson, K. R. (2012). Children apply principles of physical ownership to ideas. Cognitive Science, 36, 1383-1403. doi:10.1111/j.1551-6709.2012.01265.x

Sidanius, J., \& Pratto, F. (1999). Social dominance theory: An intergroup theory of social hierarchy and oppression. New York, NY: Cambridge University Press.

Silk, J. B. (2007). Social components of fitness in primate groups. Science, 317, 1347-1351. doi:10.1126/ science. 1140734

Smith, C. E., Blake, P. R., \& Harris, P. L. (2013). I should but I won't: Why young children endorse norms of fair sharing but do not follow them. PLOS ONE, 8, e59510. doi:10.1371/journal.pone.0059510

Spelke, E. S. (2015, March). Discussion presented in S. Gülgöz (chair), Developing a concept of social power. Symposium at the Biennial Meeting for Society for Research in Child Development, Philadelphia, PA.

Thomsen, L., Frankenhuis, W. E., Ingold-Smith, M., \& Carey, S. (2011). Big and mighty: Preverbal infants mentally represent social dominance. Science, 331, 477480. doi:10.1126/science.1199198

Tomasello, M. (2009). Why we cooperate. Cambridge, MA: MIT Press.

Vaish, A., Grossmann, T., \& Woodward, A. (2008). Not all emotions are created equal: The negativity bias in social-emotional development. Psychological Bulletin, 134, 383-403. doi:10.1037/0033-2909.134.3.383

Wellman, H. M. (2014). Making minds: How theory of mind develops. New York, NY: Oxford University Press.

Wellman, H. M., \& Gelman, S. A. (1992). Cognitive development: Foundational theories of core domains. Annual Review of Psychology, 43, 337-375. doi:10.1146/annurev.ps.43.020192.002005

Wellman, H. M., \& Miller, J. G. (2008). Including deontic reasoning as fundamental to theory of mind. Human Development, 51, 105-135. doi:10.1159/000115958

Williamson, R. A., Meltzoff, A. N., \& Markman, E. M. (2008). Prior experiences and perceived efficacy influence 3-year-olds' imitation. Developmental Psychology, 44, 275. doi:10.1037/0012-1649.44.1.275

Wright Cassidy, K., Cosetti, M., Jones, R., Kelton, E., Meier Rafal, V., Richman, L., \& Stanhaus, H. (2005). Preschool children's understanding of conflicting desires. Journal of Cognition and Development, 6, 427-454. doi:10.1207/s15327647jcd0603_6

Zmyj, N., Buttelmann, D., Carpenter, M., \& Daum, M. M. (2010). The reliability of a model influences 14-montholds' imitation. Journal of Experimental Child Psychology, 106, 208-220. doi:10.1016/j.jecp.2010.03.002

\section{Supporting Information}

Additional supporting information may be found in the online version of this article at the publisher's website:

Appendix S1. List of Vignettes Used for Each Dimension in Studies 1 and 2

Appendix S2. Sample Vignette for Study 2

Appendix S3. Scripts Used for Vignettes in Study 3, Describing Benevolent Power 